\title{
The Application of PLC in Sewage Treatment
}

\author{
Huijun Zhu, Xinglei Qiu \\ School of Energy and Power Engineering, Jiangsu University, Zhenjiang, China \\ Email: 1621361576@qq.com
}

How to cite this paper: Zhu, H.J. and Qiu, X.L. (2017) The Application of PLC in Sewage Treatment. Journal of Water Resource and Protection, 9, 841-850. https://doi.org/10.4236/jwarp.2017.97056

Received: April 11, 2017

Accepted: June 19, 2017

Published: June 23, 2017

Copyright $\odot 2017$ by authors and Scientific Research Publishing Inc. This work is licensed under the Creative Commons Attribution International License (CC BY 4.0).

http://creativecommons.org/licenses/by/4.0/

\begin{abstract}
The environmental protection has become one of the factors that affect and restrict the development of human society. With the continuous development of industry and the rapid increase of urban population, a large number of industrial and domestic sewage discharges into rivers and lakes without treatment, so that the environment and the application of water are seriously polluted. In this paper, the principle and characteristics of PLC (PLC is the abbreviation of Programmable Logic Controller) are introduced; the process of PLC sewage treatment is expounded, and the application of PLC in sewage treatment is described.
\end{abstract}

\section{Keywords}

PLC, Sewage Treatment, Application

\section{Introduction}

Water pollution is one of the urgent problems to be solved worldwide, especially in china. At present, Chinese per capita water resources are seriously lacking. Chinese population accounts for $21 \%$ of the world, but only about $6 \%$ of the world's water resources were in China. Many cities in China are seriously short of water, which seriously affects people's daily life.

Chinese sewage treatment began in the $70 \mathrm{~s}$ of last century. At that time, it has begun to make use of abandoned rivers, swamp and the surrounding city to build a stable pond for sewage. According to the literature at that time, the quantity of the stable ponds is 38 . It can process 1 million 730 thousand tons of sewage daily. In 1980s, Chinese government began to tilt to environmental protection. It promoted a large number of sewage treatment facilities in cities. Chinese first large-scale civic sewage treatment plant-Tianjin Jizhuangzi sewage treatment plant which can daily process 260 thousand tons of sewage was put into operation in April 1984. From 1985, with deepening of the comprehensive management of urban environment and increasing the intensity of water pollu- 
tion control, the construction of urban sewage treatment facilities has experienced a period of high development [1]. From 1995, Chinese government attached more important to water pollution control of the "River" (Huaihe, Haihe River and Liaohe River), the "Lake" (Taihu, Chaohu, Dianchi) and the Bohai sea area. China also gave more corresponding funding and technical support to sewage treatment. According to statistics, by the end of 2000, China has built 427 municipal sewage treatment plants which included 282 secondary treatment plants. The treatment rate of secondary treatment plants is only about $15 \%$. Thus, the current situation of Chinese sewage treatment is not ideal. The rate of sewage treatment is very low.

At present, the comprehensive management level of sewage treatment in China is far behind that of developed countries. In developed countries, the use of advanced automatic control instrumentation, PLC and industrial configuration software make sewage treatment automation and achieve the central control room unattended, greatly improving production efficiency and reliability. Compared with the developed countries, China started to study the automatic control of wastewater treatment later.

Whether developed or developing countries, the compliance rate of sewage treatment is closely related to the number of sensors, instruments, control devices used in the process of sewage treatment and the degree of comprehensive automation.

Now PLC plays a very important role in the actual industrial control [2]. Typically, the PLC technology is applied to modern sewage treatment. If we use PLC technology reasonably, there will be plenty of advantages. Comparison the traditional sewage treatment plant by adopting manual control, PLC system greatly improves the degree of automation of wastewater treatment [3]. The operator's workload is greatly reduced. The labor intensity is greatly reduced. The data processing and charting of computer makes sewage treatment achieve scientific and modern in management. The adoption of a PLC system allows the rational use of energy and equipment to save energy, reduce energy consumption and achieve significant economic benefits. The PLC system is applied to the sewage treatment plant, so it means that modern high and new technology has been adopted in the process, equipment and management, which has greatly promoted the scientific progress of the industry and created the obvious social and economic benefits.

\section{The Principle Analysis of PLC}

\subsection{The Principle of PLC}

PLC is the abbreviation of Programmable Logic Controller. Its main way of working is to rely on internal procedures. In order to make PLC control the circuit, it is necessary to write a control program according to the actual needs [4]. Then implanting the program into chips to connect the circuit and the chip, you just can complete the corresponding control function [5]. Through the actual survey it is found that there are many PLC devices in the current market. Most 
of them are produced by foreign companies. If our country wants to use it, we must import from abroad. This phenomenon has affected the application of PLC in our country to a great extent. In particular, different PLC chips, with different characteristics, can be written in different languages. But our technical staffs working on the actual programming usually choose $\mathrm{C}$ language and other high-level language to write programs. Essentially, PLC is able to complete the corresponding control function mainly due to relying on logic controller. In the current digital circuit, the digital signal controls the work of electronic components. There is only 0 or 1 of the two states in the digital signal of the circuit. According to the actual needs of the control, as long as designing a scientific and rational procedure, PLC will work on the entire circuit control, according to the contents of the program [6].

\subsection{Features of PLC}

Compared with the traditional computer, the most distinctive feature of the PLC chip is its small size. It can also achieve the control function of the computer. Although there is a certain difference in the performance compared with the ordinary computer, there are low performance requirements in the actual industrial control. Typically, only the control of the device to run and stop requires very little computation. Therefore, the lower performance of PLC devices can still meet the needs of practical use very well. In addition the PLC chip program is relatively simple. In order to facilitate the PLC programming, there have been many applications. Not only can the use of the software complete the design of the program simply, but also can carry out simulation and emulation. For PLC applications, the software have very important effect. Nowadays, most of PLC programming will use these applications to improve the efficiency of programming. The application of PLC also is flexible. Because of its relatively small size and standard IC packaging, it can be put in the designated place based on the actual needs of the control. In the actual application process, welding a slot in the circuit board and inserting the chip into the circuit directly can realize the corresponding control function. When there is a problem in the chip, the chip can be replaced directly without changing anywhere of the circuit [7].

\section{Brief Introduction of PLC Sewage Treatment Process}

Sewage from the water system initially removes large objects through the coarse grid cleaning machine. In the sand tank system, the fine grid drum cleaning machine further purify the fine particles in the sewage and filter the fine sand particles in the sewage into the oxidation ditch reaction tank. In the oxidation ditch system, carrying out the biochemical treatment is to decompose the harmful substances in the sewage. This process uses a number of chemicals to enhance the treatment effect, such as compound alkali, chlorine, oil flocculants, in order to remove the oil, disinfection, adjust $\mathrm{pH}$ value. At the same time, the system is equipped with dissolved oxygen meter ultrasonic detector. Use it to detect oxygen content in the sewage, lately control the operation of the frequency con- 
verter according to the value of the feedback to the PLC to change the dissolved oxygen content in the sewage. The role of the submersible mixer is to promote the flow, so that the oxidation ditch sewage and activated sludge are mixed in a violent agitation to make the biochemical reaction more fully, in order to maximize the decomposition of harmful components in sewage. The treated sewage enters the sedimentation tank and makes physical precipitation under the action of mud scraper. In order to strengthen the effect of precipitation, adding coagulants and flocculants at the same time allows miscellaneous settled more easily by strong adsorption effect by polymer flocculants. After treated by the sedimentation tank sewage finally reaches the dehydration section, and then the water is drained by the centrifugal dewatering machine [8].

\section{Applications of PLC in Sewage Treatment}

Take a large enterprise sewage project as an example to introduce the use of PLC in sewage treatment project. The project covers an area of about $350 \mathrm{~m}^{2}$. Sewage treatment capacity is $950 \mathrm{~m}^{3} / \mathrm{d}$. It adopts biofilm process. The concentration of COD, BOD in sewage was $320 \mathrm{mg} / \mathrm{L}, 240 \mathrm{mg} / \mathrm{L}$. In order to realize the automatic operation of the sewage project, the electrical control system adopts PLC as the core [9].

\subsection{The Working Principle of PLC Sewage Treatment}

Industrial sewage treatment system of the electrical control system diagram is shown in Figure 1. As the core controller, PLC controls the equipment to run or stop and its speed by detecting input of the operation panel button and input of all kinds of sensors.

\subsection{The Control of PLC to Grid Units}

The device of the grid well unit comprises a grid well lifting pump, a floating ball liquid level controller, a coarse grid and a floating ball liquid level transmitter. Its role is to remove particles and suspended solids in sewage. The liquid level transmitter is used to measure the liquid level difference in front and at the back

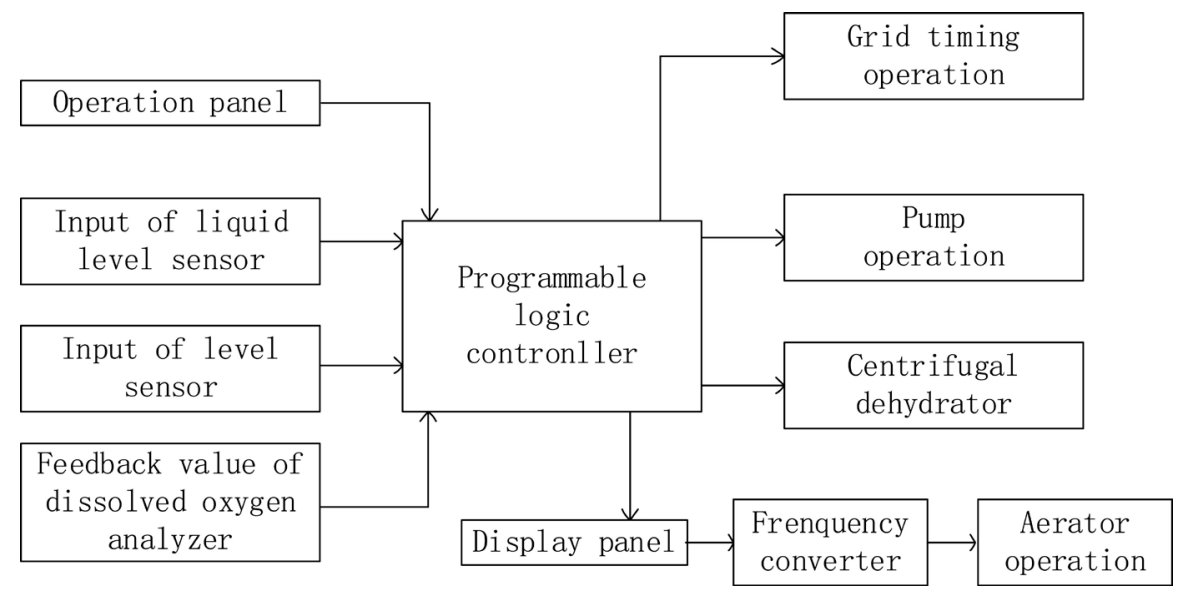

Figure 1. Control system diagram. 
of the coarse grid. When the value is greater than $10 \mathrm{~cm}$, the coarse grid starts running. When the sewage station is in automatic operation (00001 normally closed point is connected), the instruction XFER(70) makes analog signals into digital quantity, store in DM0002. Then SUB(31) commands that the input signal 2 transmitters in the program made a comparison to attain HR01. Later, the instruction CMP(20) compares with the preset value (\#2000), (\#0800) of comparison in procedures respectively. When the detection value exceeds the set value (\#2000), the internal relay and the output point $1,000,120,000$ are switched on. Thereby connecting the coarse grid contactor, coarse grid starts operation. When the detection value is smaller than the set value ( $\# 0800$ ), the internal relay 20,001 is switched on, the coarse grid stops running.

As shown in the Figure 2.

\subsection{The Control of PLC to Biochemical Pool Unit}

Biochemical pool unit mainly includes the blower, dissolved oxygen detector, electric butterfly valve, biochemical pool lift pump, floating ball level controller, its main role is to reduce the content of COD, BOD.

The energy consumption of biochemical treatment in sewage treatment plant is mainly concentrated in aeration tank [10]. PLC technology was used to improve the aeration process. The main technical routes are as follows: When the automatic/manual/automatic remote control on the control panel turns to con-

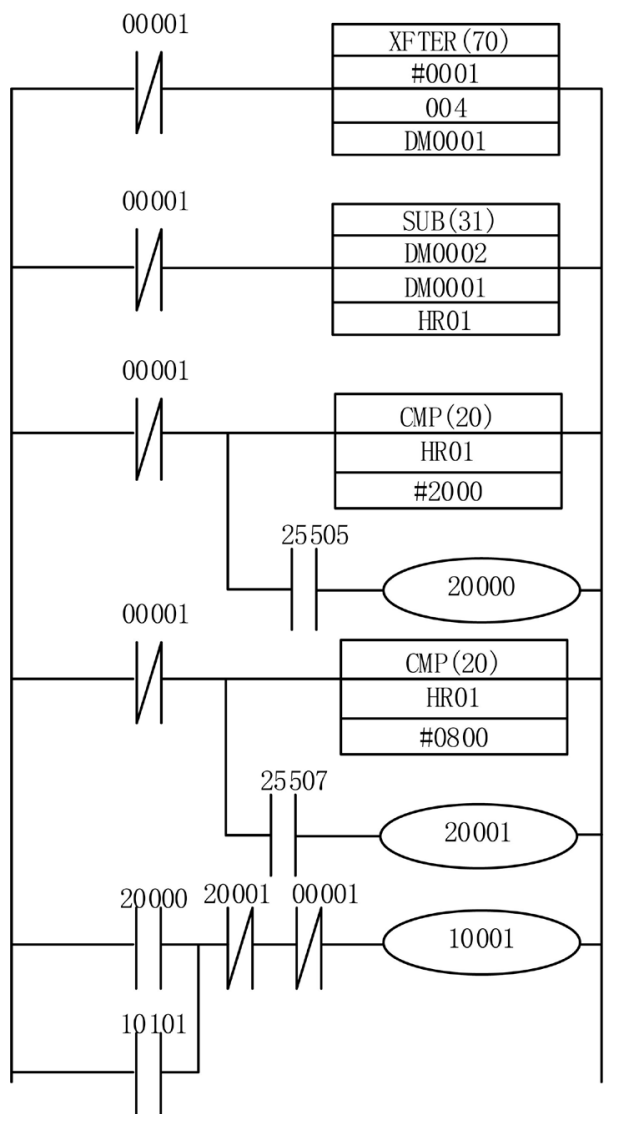

Analog acquisition

\section{Subtract}

Comparison

More than the output

Comparison

Less than the output

The coarse grid control

Figure 2. Grid well PLC ladder diagram. 
trol position, PLC can receive analog signal of dissolved oxygen detector. After signal conversion, it is compared with the set value. If the concentration of oxygen in the sewage is less than $0.5 \mathrm{mg} / \mathrm{L}$, the electric butterfly valve is opened and the blower runs, then aeration starts. When the oxygen concentration in the sewage is greater than $2 \mathrm{mg} / \mathrm{L}$, the blower stops aeration and the electric butterfly valve closes. The corresponding PLC ladder diagram is shown in Figure 3. Instruction XFER (70) converts the analog signal to digital quantity and stores it in DM0003, then the CMP (20) command is compared with the preset value (\#0500) in the program. When the detection value is less than the set value, the internal relay 20,002 is switched on and the electric butterfly valve starts to open. After $15 \mathrm{~s}$, the electric butterfly valve fully open. When the output point 10,101 is connected, the blower starts running. With the continuous aeration of the blower, the oxygen concentration in the sewage is increasing. When the analog signal conversion value is greater than the set value (\#1800), the internal relay 20,003 is switched on, the blower stops running, and then the electric butterfly valve is closed, the aeration process ends [11].

As shown in the Figure 3.

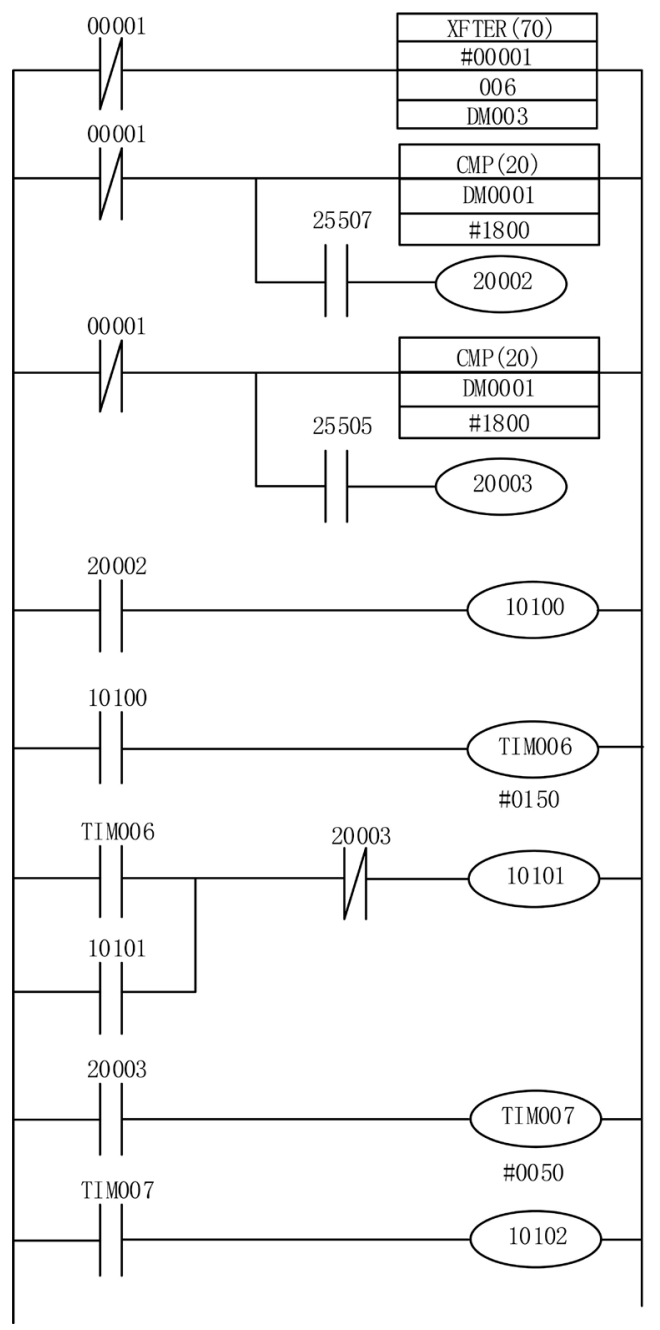

Analog acquisition Comparison

Less than the output Comparison

More than the output

Butterfly value open Delay

Blower control

Figure 3. Biochemical pool PLC ladder diagram. 
After treated, the concentration of COD, BOD were $90 \mathrm{mg} / \mathrm{L}, 50 \mathrm{mg} / \mathrm{L}$. The result reaches emission requirements [9].

\section{Conclusions}

Compared with the traditional manual control sewage treatment plant, there are several advantages in applying PLC to the sewage treatment. As shown below:

1) The workload of the operator is greatly reduced and the labor intensity is greatly reduced in PLC system.

2) Using the computer to process the data and make the chart makes the sewage treatment more scientific in management.

3) The use of PLC system for the rational use of energy and equipment saves energy, reduces energy consumption, and achieves obvious economic benefits.

4) The PLC system is applied to the sewage treatment plant and adopts the modern high and new technology in the process, equipment and management, which has greatly promoted the scientific progress of the industry and created the obvious social and economic benefits [12].

In the sewage treatment control system, the field control is the key, but the field control is mainly completed by the PLC system, so how to use PLC technology reasonably and effectively has become the focus and difficulty of the application.

As everyone knows, the characteristic of PLC is stable and reliable control, simple programming, but the program memory and instruction resources are limited. It cannot carry out too complicated sewage treatment program. But sewage treatment has various steps and each actuator is complex, not easy to coordinate each other. Therefore, the easy use of PLC programming and the complexity of the control on the formation make a contradiction.

If the use of conventional PLC is centralized control mode, the needs to handle all the steps of the implementing agencies are concentrated on a total PLC; the work line only needs one large PLC to meet all of input and output points. But this control is not reasonable, not only because of the huge investment (the cost of a large PLC is much larger than that of many small PLC), but also because it is not conducive to the preparation and commissioning of PLC program code. In accordance with modern control theory, the more control units are configured in a single control system, the less reliable the control is.

Therefore, in order to reduce the complexity of PLC code and enhance the reliability of the control, the control system adopts centralized-decentralized control mode. It just means that each processing step is controlled by a PLC. The PLC separately controls all actuators of the step. At the same time, the longrange PC do unified control to all distributed PLC. From the structure, the control system of the working line adopts the control network structure based on Ethernet. From the function, the whole working line control system can be divided into control system hardware module and software module.

Through the use of programmable logic controller which greatly improves the 
degree of automation of wastewater treatment. Some western countries have built a number of automated working lines based on the PLC chip. Only needing a small amount of technical personnel, it just can achieve twenty-four hours of uninterrupted operation. It can be seen that PLC is now plays a very important role in the actual industrial control. However, due to the limit of technology, it is not very common for sewage treatment in China to realize the automatic operation. The main reason of this phenomenon is that PLC application is poor. If wanting to solve this problem well, China must introduce foreign advanced equipment and technology according to the actual situation of China's industrial production and transform the sewage treatment line.

\section{Personal Opinions}

The automatic control system introducing advanced foreign technology to wastewater treatment plant in recent years in china has been widely used in distributed control system. It also applies detecting instruments of a high degree of automation, new technology and new equipment, achieving good results. At present china has built dozens of sewage treatment plant. According to their operation situation, the control system which includes the central computer and PLC has a good adaptability, as the dominant form of domestic sewage treatment automation system application. But there are still the following problems:

1) The function and accuracy of some automatic testing equipment, instruments and valves in sewage treatment automatic control is not perfect. In practice they cannot reach to the desired requirement. The error is also very large. Therefore, if relying only on the testing equipment to determine the situation of sewage treatment and the implementation of automatic control, it is difficult to achieve the standard of quality and the purpose of saving energy.

2) Although many wastewater treatment plants consider ORP, DO, $\mathrm{pH}$ value as a parameter to control water quality and regulate aeration, when the controller is unable to find the ORP feature points, the sewage treatment system will still control the whole process according to time.

3) The control and regulation of water quality exists lag problems. For example, when controlling aeration of the air blower by the volume of DO in aerobic pool, due to the biochemical treatment system itself is a dynamic balance, workers found DO (low or high) through the online real-time monitoring of operating and achieve the increase (or reduce) the amount of aeration through adjusting the blower impeller speed. In this process, the lag between monitoring of the DO value and regulation of air blower may cause a result that the blower cannot accurately provide the volume of aeration according to the actual concentration of dissolved oxygen in aerobic tank, so it is difficult to really achieve the purpose of energy saving.

4) Equipment maintenance is difficult. For example, $\mathrm{pH}$, sludge concentration meter, mud level meter has a strict maintenance requirements including regular cleaning, contact probe calibration, maintenance equipment loss and so 
on. Additionally, at the present stage Chinese sewage treatment plants mostly use imported expensive equipment. To a certain extent, It increases the investment cost of sewage treatment plant.

How PLC will continue to survive and develop in industry?

For a long time, PLC has always been in the main battlefield of industrial automation control and provides reliable control applications for a variety of automated control equipment. It can provide a safe and reliable solution for the application of automatic control, and it is suitable for the needs of automation in the current industrial enterprises. But on the other hand, PLC also has to rely on other new technologies to face the impact of the gradual decline in its market share, especially the impact caused by industrial PC. PLC needs to solve the problems which are still the adoption of new technologies, system openness and price [13]

In this century, PLC will be multi-functional, integrated, intelligent, standardized and open. Although suffering from some challenges, PLC automation control system simultaneously absorbs their advantages to make mutual integration and innovation. It will exist with other advanced control methods in the next period of time [14].

How to continue the development of wastewater treatment in the computer age?

With the development of the society, the water resource is in short supply. The discharge of sewage treatment is not the ultimate goal of sewage treatment. The ultimate goal of sewage treatment should be the regeneration and utilization of water resources. Therefore, the depth of sewage treatment needs to be further strengthened.

With the development of computer technology, industrial automation will be the trend of the times [3]. The low cost industrial control automation based on industrial PC will become the mainstream. Therefore, intelligent sewage treatment will be the inevitable choice of industrial wastewater treatment. Online monitoring is very important to monitor the running state of sewage treatment facilities. Only having the equipment monitoring can do all-weather housekeeper. For example, whether does the drought fan have run or not? How long does the drought fan have operated? How much is electricity? These details are to be refined through scientific technological means and the Internet means for real-time monitoring. Therefore, the sewage treatment industry will achieve the ultimate goal of machine replacement finally.

At the same time, equipment standardization is also a direction. We need to do a good job of equipment standardization so that sewage treatment efficiency can be greatly improved. When the equipment have problems, it is easy to be replaced. Technical exchanges in the same industry will also be more convenient, data sharing will be more accurate That is what I think is the future of technology.

\section{References}

[1] He, C.J. (2008) Application of Automatic Control System in Wastewater Treatment. 
Environmental Science and Management, 33, 89-91.

[2] He, Z.Z. (2016) Talking about the Application of PLC Automatic Control System in Sewage Treatment, Information \& Communication in Vol. 10.

[3] Dong, W. (2016) The Standard Combination of DCS and PLC in Petrochemical Large Sewage Treatment Enterprises. Standards and Quality of Chinese Petroleum and Chemical Engineering, 17.

[4] Yao, H.L. and Yao, G.S. (2006) PLC Application and Problems in Application. Journal of Career Technical College, No. 2, 74-76.

[5] Qin, X.F. (2008) The Future Development Trend of PLC-Open Multifunctional Integrated PLC. Programmable Controller and Factory Automation, No. 4, 31-32.

[6] Tao, W.M. (2014) PLC Analysis and Its Application in Industry. Journal of Railway Institute (Social Sciences Edition), 3.

[7] Wang, F.C. (2010) A Brief Description of the Problems in the Application and Use of PLC. Media, No. 10, 173-174.

[8] Li, G.W. (2014) PLC Application in Sewage Treatment Plant. Theoretical Research, Taiyuan.

[9] Zhao, X., Zhao, L. and Wang, Y. (2003) Application of PLC in Wastewater Treatment Engineering. Water Supply and Drainage, 29.

[10] Yu, L.H. (2005) The Application of PLC in the Control System of the Sewage Treatment Plant. Automation and Instrumentation, Vol. 5.

[11] Sun, X. (2003) The Application of PLC in Sewage Treatment. Engineering of Water Supply and Drainage, 10.

[12] Huang, C., Zhang, W. and Zhang, H. (2011) PLC Application in Sewage Treatment. Energy and Environment.

[13] Xu, D. (2004) The Development Trend of PLC. Science and Technology, No. 20, $65-68,77$.

[14] Chen, J. (2004) Modern PLC Control Technology and Development. Precision Manufacturing and Automation, No. 4.

\section{Scientific Research Publishing}

Submit or recommend next manuscript to SCIRP and we will provide best service for you:

Accepting pre-submission inquiries through Email, Facebook, LinkedIn, Twitter, etc. A wide selection of journals (inclusive of 9 subjects, more than 200 journals)

Providing 24-hour high-quality service

User-friendly online submission system

Fair and swift peer-review system

Efficient typesetting and proofreading procedure

Display of the result of downloads and visits, as well as the number of cited articles

Maximum dissemination of your research work

Submit your manuscript at: http://papersubmission.scirp.org/

Or contact jwarp@scirp.org 